\title{
Six years' experience of sharing the care of Edinburgh's drug users
}

\author{
Judy Greenwood
}

\begin{abstract}
Six years ago, Edinburgh's community diug problem senvice establtshed a model of shared care between diug speciallsts and general practitioners who were encouraged to prescribe orol methadone and other chug subettlutes in an aftempt to reduce drug injecting and the spread of HIV in a clly with a high seroprevalence rate. Of Edinburgh's GPs, $70 \%$ now prescribe for oround 1200 diug users who have altered thelr pattem of drug taking, with a makked shill away from injecting orug use, and fowards oral pharmaceutical druges. HIV rates among now referrals to the service have follen from $21 \%$ to $8 \%$.
\end{abstract}

In 1988, Edinburgh's Community Drug Problem Service (CDPS) was established to complement existing non-statutory drug agencies, equipment exchanges and local health education initiatives. It aimed to alter the pattern of drug use and associated high-risk behaviours in a city with a high prevalence of HIV among its intravenous drug users.

A shared care approach was adopted whereby general practitioners were encouraged to offer physical health care and substitute prescribing of oral oplates/or benzodiazepines, or both, in doses negotiated by the Community Drug Problem Service which would support the GP and offer the drug user regular counselling, and random urinalysis to encourage beneficial changes in lifestyle and drug use.

At that time, the use of substitute prescribing was controversial, although the Advisory Council on the Misuse of Drugs had recommended it as one approach to harm-minimisation in the face of HIV (Department of Health and Social Security, 1988). Department of Health guidelines on Drug Misuse and Dependence (1991), and an update of the Advisory Council's Aids and Drugs Misuse (Department of Health and Social Security, 1993) further emphasised the important role of GPs with drug-using patients.

In 1988, it was unclear if GPs would be prepared to work with and prescribe for drug users. Nor was it clear if substitute prescribing of oral drugs would attract and keep drug users in contact with medical services and promote behavioural change.
Details of how the new drug service was set up and how general practitioners were persuaded to prescribe are described in earlier papers (Greenwood, 1990; 1992).

\section{The current service}

The service has become sectorised and reglonal, serving a population of 750000 . The team consists of two consultant psychiatrists, 13 community psychiatric nurses, three part-time clinical assistants, senior social worker, a psychologist and four administrattve staff. Although referrals are made to the hospital, most patients are seen in the community. After assessment, a management meeting determines the proposed treatment including medication if relevant, which is communicated to the patient's GP in writing. Patients are then followed up by their keyworkers weekly or according to need.

Patients might be referred to the methadone clinic to take medication on site for three consecuttve days, followed by three weeks of central prescribing before being returned to their own doctor. For a particularly chaotic drug user or one having problems with their GP, the Community Drug Problem Service would continue to prescribe centrally, but this would be the exception.

The service has remained exclustvely outpatient. A long-awaited community-based detoxification/crisis hostel is proving a popular resource for clients now bored by years of methadone maintenance.

\section{Findings}

\section{Referral data}

Referrals have continued to rise each year (Table 1), and totalled 2934 from 1988-1993, with $60 \%$ of referrals from GPs. High referral rates have been associated consistently with areas ranked high in social deprivation and unemployment. Of referrals, $71 \%$ were male, with $17 \%$ of patients working at the time of referral; $80 \%$ had a past criminal record and $61 \%$ had been in prison. 
Sixty per cent had experienced significant family disruption in childhood.

\section{Medication}

In $1988,23 \%$ of patients were offered counselling only. Most subsequent defaulters were from this group. By 1992, 87\% of the active caseload were on a prescription, usually from their GP. The proportion varied with $64 \%$ of patients under 20 on a prescription, contrasting with $93 \%$ of 25-29year-olds.

An audit on medication carried out in 1992 on 297 CDPS current attenders showed that around half were on stable levels of medication (maintenance), and half were on reducing regimes of methadone. In addition, $66 \%$ of the sample were also on benzodiazepines. The service prescribes centrally for 150 difficult patients, or, exceptionally, for those patients with a doctor who refuses to prescribe. A recent survey confirmed that 1200 drug users receive medication from $70 \%$ of Edinburgh's GPs (Bury, 1994).

\section{Counselling}

Most work with drug users involves dealing with underlying depression, chronic anxiety and paranoia, low self-esteem, social phoblas, past sexual abuse, unresolved grief, sexual and marital problems, family work and all the practical problems that accompany a chaotic lifestyle. The work is often frustrated by those patients too immature or damaged to sustain persistent change. The service has yet to find adequate ways of routinely measuring these behavioural and emotional changes.

\section{Reduction in drug injecting and sharing equipment}

Although socio-demographic details of referrals to the Community Drug Problem Service remained similar over the years, the pattern of drug use at the time of referral changed progressively, especially in the first five years of the service.

The proportion of drug users who had ever shared injecting equipment fell from $85 \%$ in 1988 to $51 \%$ in 1993 . Sharing equipment in the past

Table 1. Referral rates

\begin{tabular}{lcc}
\hline & Number referred & Number aftended \\
\hline 1988 & 138 & $86(62 \%)$ \\
1989 & 292 & $205(70 \%)$ \\
1990 & 415 & $268(65 \%)$ \\
1991 & 475 & $302(64 \%)$ \\
1992 & 774 & $472(61 \%)$ \\
1993 & 840 & $530(63 \%)$ \\
Total & 2934 & $1863(64 \%)$ \\
\hline
\end{tabular}

month fell from $39 \%$ to $13 \%$ in the same time period.

The proportion of new referrals who had ever injected fell from $97 \%$ in 1988 to $43 \%$ in 1993. From those who had ever injected, injecting in the month prior to referral fell from $88 \%$ to $14 \%$ over the same years. These changes are reflected in an earlier study comparing referral cohorts from different years (Grifin et al, 1993).

A research study of two cohorts of CDPS patients in treatment after 6 months $(n=74)$ and 24 months ( $n=57)$ show that injecting rates continued to decrease with $90 \%$ and $72 \%$ respectively never injecting in the month prior to interview.

\section{HIV seropositivity rates}

The HIV seroposittve rates of CDPS referrals tested prior to referral fell from 21\% in 1988 to $8 \%$ in 1993. The overall Lothian HIV seroconversion rate from injecting drug use showed a similar fall from 1986.

Condom use did not change in the same time interval, suggesting that there had been no equivalent move towards safer sexual behaviour despite good local public health education programmes about AIDS. The CDPS research study also showed that around half continue never to use condoms after treatment, and less than $15 \%$ use them regularly.

These changes are likely to be due to a heightened awareness of the dangers of HIV. good local health education programmes, personal knowledge of people with AIDS, and increased availability of needle exchanges.

The drug service upheld the ethos of discouraging injecting by threatening to withhold scripts if regular injecting continued.

This attitudinal and behavioural change is confirmed by Haw's study (1993), contrasting the low rate of injecting in Edinburgh with the high rate of injecting the same drug in Glasgow. less than 50 miles away (Fig. 1). This figure also confirms the swing away from heroin use in Edinburgh. Glasgow's rate of injecting remains similar to that in Edinburgh in 1988 before the prescribing service was established. A new prescribing drug service has just been established in Glasgow and it will be interesting to see if similar changes in the pattern of drug use occur there.

\section{Comments}

Has the CDPS achieved its aims?

The rise in GP prescribing for drug users has been gratifying. Because of the high prevalence of HIV infection in Edinburgh, it might have been easier to convince GPs of the empirical value of substitute prescribing of drug substitutes as a 

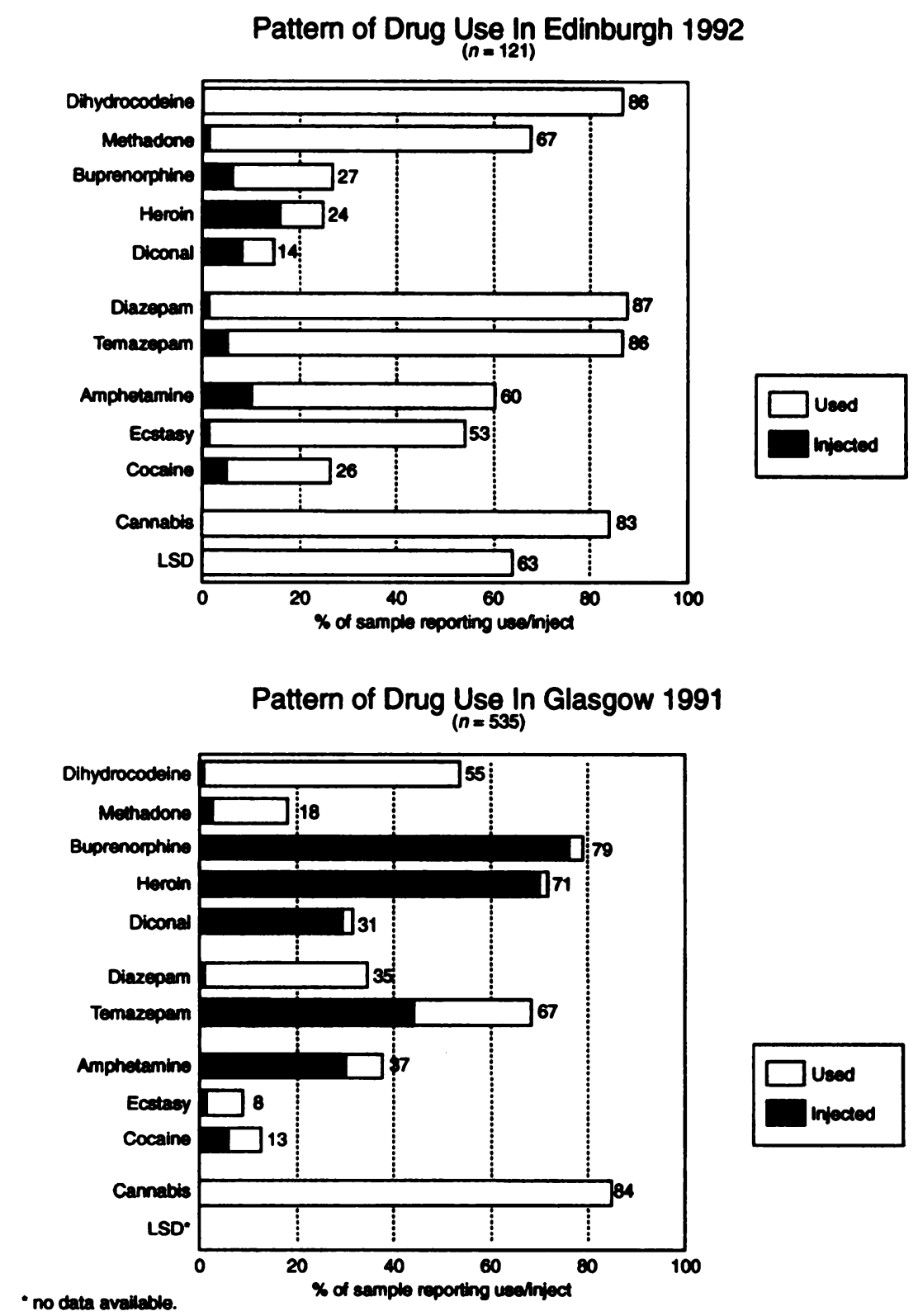

Fig. 1

public health strategy. But we believe that by offering GPs specialist support, and more latterly a primary care facilitator in HIV/AIDS and drugs, more GPs have been prepared to share the burden of treating drug users, albeit not uniformly among all practices, because of the preponderance of drug users in deprived areas. As a result, the specialist drug service has been able to deal with more patients than would have been possible, with conventional centralised prescribing service.

Whether the change in prescribing practice has contributed to changes in injecting rate and the swing towards oral drug use in Edinburgh cannot be proved, but the changes occurred contemporaneously.

In addition to the falling rates of injecting noted at the time of referral to the drug service, and the 
continued fall during treatment in the CDPS research study, changes in injecting behaviour are confirmed by Haw (1993) and Shannon (1992).

Of 488 Lothian drug users notified to the Scottish Office database in 1991-92, only $20 \%$ were current injectors (National Health Service in Scotland, 1992).

Newly reported cases of both HIV and hepatitis B started to fall in Lothian in 1987 and 1986 respectively, before the needle-exchange and drug service were established, but the reduction in injecting behaviour thereafter is likely to have contributed to maintaining this improvement. In contrast, rates of new HIV infections from homosexual and heterosexual spread have not shown the same decrease.

Society's attempts to tackle the escalating drug problems by punishment and reduction in supplies of drugs has clearly failed, prompting high-ranking members of the police and press to 'think the unthinkable' about legalisation (The Independent, 1993). We believe that in Lothian. we have started diverting some of the control of local drug supplies into the hands of the medical profession, without going as far as legalisation.

Although most of our patients remain on drugs. they are on safer, long-acting oral pharmaceutical preparations, and half are on gradual reduction programmes. The majority now rarely inject, with a consequent reduction in risk of contracting HIV and other morbidity associated with injecting drug use.

\section{References}

BURY, J. (1994) HIV Infection and Drug Misuse in Lothian General Practice. Report on Epidemiological Questionnatre 1993. Lothian Health Authority.

DEPARTMENT OF HEALTH (1991) Drug Misuse and Dependence: Guidelines on Clinical Management. London: HMSO.

DEPARTMENT OF HEALTH AND SOCIAL SECURTY (1988) AIDS and Drug Misuse, Part I. Report by the Advisory Councll on the Misuse of Drugs. London: HMSO.

- (1993) AIDS and Drug Misuse Update. Report by the Advisory Council on the Misuse of Drugs. London: HMSO.

GREENwOOD, J. (1990) Creating a new drug service in Edinburgh. Brttish Medical Joumal, 300, 587-589.

- (1992) Persuading general practitioners to prescribe good husbandry or a rectpe for chaos? Brittsh Joumal of Addiction, 87, 567-575.

GRIFTIN, S.. PETERS, A. \& REID, M. (1993) Drug misusers in Lothian: changes in injecting habits 1988-90. Brittsh Medical Journal, 306, 693.

HAw, S. (1993) Pharmaceutical Drugs and Iliktt Drug Use in Lothian Region. Edinburgh: Centre of HIV/AIDS and Drug Studies.

INDEPENDENT (1993) Editorial, 14 May 1993.

NAmonal Henlth Service In Scotund (1992) Scottsh Drug Misuse Database Bullettr. Information and Statistics Dtvision. National Health Service in Scotland. Edinburgh. Shannon, H. (1992) Lothian Drug Misuse Database: general report. Edinburgh.

Judy Greenwood, Consultant Psychiatrist, Community Drug Problem Service, Royal Edinburgh Hospital, Edinburgh EH1O 5HF 